\title{
Biogeochemical cycling of iron and carbon from forested environments to coastal waters and sediments
}

\author{
CELESTE CECILIA INDIDI KELLOCK ${ }^{1}$, CRAIG \\ SMEATON $^{2}$, NADEEM SHAH ${ }^{3}$, WILLIAM AUSTIN ${ }^{2}$ AND \\ CHRISTIAN SCHRÖDER ${ }^{1}$ \\ ${ }^{1}$ University of Stirling \\ ${ }^{2}$ University of St Andrews \\ ${ }^{3}$ Forest Research \\ Presenting Author: celeste.kellock@stir.ac.uk
}

Lateral transport of organic carbon across the terrestrialaquatic interface is often overlooked and under studied. There is strong evidence that iron facilitates organic carbon transport and storage in marine sediments [1] and it has been suggested that iron and carbon binding occurs before reaching the water sediment interface [2]. We explore the lateral transport of organic carbon and iron in fjord catchments from areas of forestry to coastal waters and sediments. Fjord systems have recently been identified as significant terrestrial carbon stores [3] and there is a global drive to increase forest cover. Establishing the influence of land use, specifically forestry, on coastal biogeochemical cycling is particularly important if afforestation is to help mitigate climate change impacts, and to better understand the impact of deforestation. This is relevant to Scotland and other fjord nations.

Elemental and isotopic analysis are used to determine the concentration and source of organic carbon in sea loch sediments. To gain a better understanding of the mechanisms behind terrestrial organic carbon-iron transport we use XRF, XRD and Mössbauer spectroscopy to measure the concentration and speciation of iron present. Sequential extractions allow the pairing of reactive iron and organic carbon to be better understood in fjord sediments. This project will incorporate further analytical techniques such as biomarker analysis and SEM to improve our understanding of biogeochemical cycling in fjord systems across the terrestrial-aquatic interface.

[1] Lalonde, K., Mucci, A., Ouellet, A., Gélinas, Y. (2012), Nature 483, 198-200.

[2] Faust, J.C., Tessin, A., Fisher, B.J., Zindorf, M., Papadaki, S., Hendry, K.R., Doyle, K.A., März, C. (2021), Nature Communications 12, 275.

[3] Smeaton, C., Austin, W.E.N. (2017), Geophysical Research: Biogeosciences 122, 11, 2754-2768. 